\title{
Low blood pressure is sustained during subsequent activities of daily living performed after power training in older women
} \author{
Maria-Cláudia Irigoyen ${ }^{6}$, Daniele Jardim Feriani', Marco Carlos Uchida' \\ ${ }^{1}$ Applied Kinesiology Laboratory-LCA, School of Physical Education, University of Campinas, Campinas, Brazil \\ ${ }^{2}$ Center of Health Sciences, University of Mogi das Cruzes, Mogi das Cruzes, Brazil \\ ${ }^{3}$ School of Physical Education, Catholic University of Brasília, Brasília, Brazil \\ ${ }^{4}$ Community Center for Older People of Poá, Poá, Brazil \\ ${ }^{5}$ School of Arts, Sciences and Humanities, University of São Paulo, São Paulo, Brazil \\ ${ }^{6}$ Hypertension Unit, Heart Institute (InCor), Medical School of University of São Paulo, São Paulo, Brazil
}

Hélio José Coelho-Júnior ${ }^{1,2, *}$, Bruno Rodrigues', Samuel da Silva Aguiar ${ }^{2,3}$, Ivan de Oliveira Gonçalves ${ }^{2,4}$, Ricardo Yukio Asano ${ }^{2,5}$,

The present study aimed to examine the effects of a prior session of power training on blood pressure values during tasks that mimic the activities of daily living in hypertensive and normotensive older women. A randomized crossover experimental design was used for this study. Eleven older women (age, $66.1 \pm 1.2$ years; body mass index, $26.7 \pm 4.8$ $\mathrm{kg} / \mathrm{m}^{2}$; systolic blood pressure, $133.9 \pm 23.4 \mathrm{mmHg}$ ) were recruited to participate. Volunteers were randomly underwent to a single session of physical exercise equalized by training volume, characterized by 3 sets of 8-10 repetitions in 8 different exercises. However, Power training session was performed at a higher intensity (moderate) than Sham session (rest/very, very easy). Immediately after the end of the exercise session, subjects were assigned to perform five tasks that mimic the activities of daily living. Hemodynamic parameters were recorded before and immediately after the session of physical exercise, as well as in the end of each of the tasks. Results demonstrated significant elevations in systolic blood pressure and pulse pressure values during the performance of the tasks after the Sham session. However, values were not altered in the power training session. Data of the present study indicate that an acute session of power training can maintain blood pressure values lower during the subsequent performance of tasks that mimic activities of daily living in older women.

Keywords: Hypertension, Older adults, Physical exercise, Power training, Activities of daily living

\section{INTRODUCTION}

Hypertension (HTN) is a chronic degenerative condition clinically characterized by an asymptomatic persistent elevation in arterial blood pressure values (Chobanian et al., 2003). Even if several evidence have been discussing a possible association between HTN, muscular impairment and cognitive decline (Coelho-Junior et al., 2017b; Coelho-Junior et al., 2017c), the main concern about this disease is due its strong association with the development of cardiovascular (e.g., myocardial infarction) and neurovas- cular (e.g., stroke) diseases, and, consequently, early death (Mozaffarian et al., 2015; World Health Organization, 2009). Regarding its prevalence, older women seem to be the most affected group, once American Heart Association reports indicate that $80 \%$ of American older women present a clinical diagnosis of HTN (Go et al., 2013).

Physical exercise has been widely recommended by several guidelines (Chobanian et al., 2003; Pescatello et al., 2004) to compose the nonpharmacological strategies used in the management of blood pressure values in hypertensive patients, once sys-

\footnotetext{
*Corresponding author: Hélio José Coelho-Júnior

(iD https://orcid.org/0000-0001-7482-9514

Applied Kinesiology Laboratory-LCA, School of Physical Education, University of Campinas-Avenida Érico Veríssimo, 701-Cidade Universitária “Zeferino Vaz”, Barão Geraldo, CEP 13.083-851, Campinas, São Paulo, Brazil

Tel: +55-11-29615143, Fax: +55-19-35216750, E-mail: coelhojunior@hotmail.com.br Received: May 4, 2017 / Accepted: July 28, 2017
}

This is an Open Access article distributed under the terms of the Creative Commons Attribution Non-Commercial License (http://creativecommons.org/licenses/by-nc/4.0/) which permits unrestricted non-commercial use, distribution, and reproduction in any medium, provided the original work is properly cited. 
tematic reviews and meta-analytic regressions have demonstrated that aerobic and resistance (i.e., dynamic and isometric) training, can elicit a significant decrease in blood pressure values in this population (Carlson et al., 2014; Cornelissen and Smart, 2013).

Nevertheless, the effects of physical exercise on the cardiovascular system are not circumscribed to its chronic effects, and evidence demonstrate lower blood pressure values in relation to the pre-exercise moment after an acute session of exercise (Asano et al., 2014; Coelho-Junior et al., 2017a; Macedo et al., 2014). This phenomenon is called hypotension postexercise (HPE). Indeed, significant HPE has been demonstrating by several experiments, which studied different regimes of physical exercise, including — but not limited to—aerobic (Asano et al., 2013; Asano et al., 2014; Barreto et al., 2015; Santana et al., 2013) and resistance (Brito et al., 2014; Macedo et al., 2014; Moraes et al., 2007; Moraes et al., 2012) exercises in normotensive and hypertensive subjects.

Once HPE is a transient phenomenon, which can last for up some hours after physical exercise cessation, some researchers have been discussing its external validity. Classically, chronic adaptations in the cardiovascular system from physical exercise were supposed to be a sum of the acute effects (Terra et al., 2008). Recently, evidence confirmed, at least, partially, this theory, once was demonstrated that the magnitude of HPE after aerobic (Liu et al., 2012) and resistance exercises (Moreira et al., 2016) was positively correlated with chronic changes on blood pressure values.

Despite its associations with chronic changes, some studies have been discussing if HPE may be affected by the subsequent performance of physical and/or mental activities (Hamer et al., 2006). Regarding mental activities, data have been demonstrating that blood pressure values remain lower during stressful mental tasks (e.g., Stroop test) accomplished after an acute session of exercise (Hamer et al., 2006). However, just a few experiments have tested the hypothesis that HPE is preserved during a subsequent performance of physical and mental activities (Hamer et al., 2006; MacDonald et al., 2001; Mota et al., 2009).

These studies have been performed with young and middle-aged adults, and physical efforts are commonly based on physical tasks with a high aerobic component, or even, were not controlled by the researchers (i.e., free-living workday), which limits its application in the geriatric population. Moreover, is important to mention that such studies have been investigating, predominately, the effects of aerobic and resistance exercises and the effects of other regimes of physical exercises, such as power training (PT), have not been elucidated.

It is important to mention that PT has been widely recom- mending composing the programs of physical exercise addressed for older people, once evidence suggest that muscle power decreases faster and in a larger magnitude, as well as is more associated with functionality and mobility than other physical capacities, such as muscle strength (Bean et al., 2003; Dietzel et al., 2013; Lauretani et al., 2003). Even if a substantial number of studies have been confirmed the beneficial effects of PT in the functional capacities of older adults (Ramírez-Campillo et al., 2016; Wallerstein et al., 2012), just recently, in a seminal study from our group (Coelho-Junior et al., 2017a), its acute effects in the cardiovascular system started to be elucidated. However, a question remains regarding the capacity of PT to collaborate with maintaining of lower blood pressure values during the performance of physical tasks in older adults.

Therefore, the present study aimed to examine the effects of a prior session of PT on blood pressure values during tasks that mimic the activities of daily living (ADL) in hypertensive and normotensive older women.

\section{MATERIALS AND METHODS}

In the present study, in an attempt to mimic a real environment, where the volunteer, after the session of exercise training go home and perform several tasks, was developed a crossover experimental study to elucidate if blood pressure values remain lower during the performance of the ADL after an acute session of physical exercise in comparison with a day when the volunteer did not exercise (i.e., Sham). The crossover methodology was based on the execution of two experimental sessions, an exercise session (i.e., PT) and a Sham session (i.e., SS). The SS seems to be a better approach than a control session to understand the acute effects of PT because the volunteers do not remain sitting or lying down - as occurs during control sessions-, but they are in fact, moving their body, as occurs in real life.

\section{Subjects}

After approval of the study by the Research Ethics Committee of the University of Campinas, (protocol No. 835.733) and the signature of the term of free and informed consent, 11 untrained older women (age range, 60 to 74 years) from two specialized public community health centers for older adults in a town of São Paulo city metropolitan area, in the southeastern Brazil, were recruited.

Diagnosis of HTN was not a criterion for exclusion. However, to ensure homogeneity, hypertensive $(n=6)$ and normotensive $(\mathrm{n}=5)$ patients were randomized separately. Therefore, hyperten- 
sive patients were first blinded allocated to PT or SS, and, after, in the same way, normotensive patients. For allocation of the participants in one of the 2 experimental sessions (i.e., PT or SS), a computer-generated list of random numbers was used.

Anthropometric characteristics, hemodynamic variables, morbidity data, and the average number of medications used, as well as the class of medications, are shown in Table 1. Briefly, anthropometric characteristics (i.e., weight and height) were evaluated using a body weight scale with stadiometer Filizola (Filizola, São Paulo, Brazil). In turn, information regarding the prevalence of morbidities - diseases — , use of medications and exclusion criteria data were collected from medical records (i.e., chart review) of each subject by two researchers (i.e., HJCJ and SSA) and data

\section{Table 1. Sample characterization $(n=11)$}

\begin{tabular}{lc}
\hline Variable & Value \\
\hline Age $(\mathrm{yr})$ & $66.1 \pm 1.2$ \\
Height $(\mathrm{cm})$ & $156.9 \pm 6.7$ \\
Body mass index $\left(\mathrm{kg} / \mathrm{m}^{2}\right)$ & $26.7 \pm 4.8$ \\
Systolic blood pressure $(\mathrm{mmHg})$ & $133.9 \pm 23.4$ \\
Diastolic blood pressure $(\mathrm{mmHg})$ & $75.3 \pm 7.6$ \\
Mean arterial pressure $(\mathrm{mmHg})$ & $94.8 \pm 12.2$ \\
Pulse pressure $(\mathrm{mmHg})$ & $58.6 \pm 18.0$ \\
Hypertension $(\%)$ & 55 \\
Mean of drugs & $0.5 \pm 0.8$ \\
Drug class $(\%)$ & \\
ANG II receptor antagonist & 80 \\
ACE inhibitor & 0 \\
Diuretic & 20 \\
Calcium channel blockers & 20 \\
\hline
\end{tabular}

Values are presented as mean \pm standard deviation unless otherwise indicated. $A N G$, angiotensin; $A C E$, angiotensin converting enzyme. were confronted to ensure reliability.

The diagnosis of HTN was accomplished by a specialist (i.e., cardiologist) who was not affiliated to the centers. In summary, before the participants began the activities in the centers where they were recruited, a medical consultation was conducted and an extensive list of medical exams was required (e.g., fasting blood glucose, fasting blood insulin). If the patient showed any signal of HTN, such as elevated blood pressure levels along the day, she was referred to a specialist. After specific exams, patients should return to the centers with a letter signed by the specialist confirming or not the diagnosis. The final diagnosis was signed by the head-physician of the center and a nurse updated the medical records each 6 months.

Exclusion criteria were: hormone replacement and/or psychotropic drugs use, cardiovascular disease (e.g., acute myocardial infarction, stroke, peripheral arterial disease, and transient ischemic disease), pulmonary disease, neurological or psychiatric disease (e.g., Parkinson or Alzheimer disease), musculoskeletal disorders, metabolic diseases (e.g., diabetes mellitus type II), comorbidities associated with greater risk of falls and recent history of smoking or alcohol abuse. The participants had not been involved in resistance or aerobic training in the last 12 months (i.e., untrained) (Rhea, 2004).

\section{Procedures}

The experimental design adopted in the present study can be observed in Fig. 1. In summary, after being recruited, evaluated regarding the inclusion and exclusion criteria and underwent to an adaptation period, volunteers performed the main experimental sessions (i.e., PT and SS). For the experimental sessions, volunteers

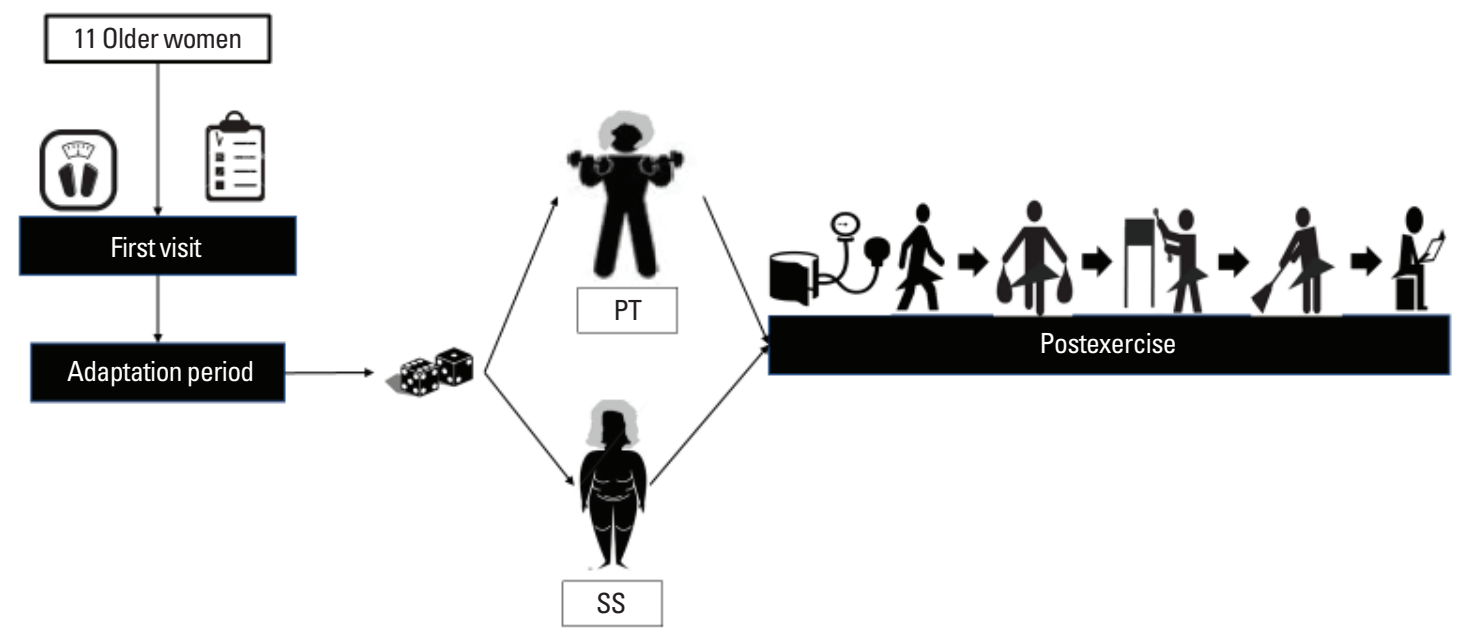

Fig. 1. Experimental design adopted in the present study. PT, power training; SS, sham session. 
reported in a fast state to the laboratory on two separate occasions separated, at least, by $96 \mathrm{hr}$. After the performance of PT and SS, subjects accomplished five tasks, which were developed to mimic ADL. To evaluate the effects of physical exercise on blood pressure behavior during the performance of ADL, blood pressure values were measured before, immediately after (IA) the end of the experimental sessions and IA the end of each one of the five tasks.

\section{Exercise protocol}

During all procedures, including physical exercise, the temperature in the laboratory was maintained between $21^{\circ} \mathrm{C}$ and $24^{\circ} \mathrm{C}$. The experimental protocols occurred under the supervision of two researchers (HJCJ and SSA), which were responsible for exercise prescription and monitoring of the exercise sessions.

Before experimental sessions, volunteers were subjected to an adaptation period to avoid any bias related to the wrong execution of the exercises and to familiarize them with the Borg scale adapted by Foster et al. (2001), with the laboratory environment, and with the researchers. The adaptation period was the same for all subjects and involved the performance of the same exercise sessions in the morning (9:30 a.m. to 11:30 a.m.), twice a week, with a minimum interval of $48 \mathrm{hr}$ between each exercise bout, during 4 weeks. Each session was composed of nine exercises, which were designed to stimulate the major muscle groups, at the intensity classified as easy in the adapted Borg scale (Foster et al., 2001), with 12-15 submaximal repetitions, avoiding fatigue, such that during the first week, volunteers performed 1 set of each exercise, and during the following weeks, they performed 2 sets of each exercise, with 1-min rest interval between each set (American College of Sports Medicine et al., 2009; Garber et al., 2011). Exercises were performed by alternating the major groups in the upper and lower extremities (alternating groups). The exercises that composed the adaptation period were: (a) seated row, (b) leg press, (c) chest press, (d) seated leg curl, (e) lateral raise, (f) calf raise, (g) arm curl, (h) triceps extension, and (i) abdominal crunch. The duration of each exercise session was approximately $50 \mathrm{~min}$. To avoid bias, elastic bands (Thera-Band, The Hygenic Corp., Akron, OH, USA) were added in the exercise routine of the adaptation period. Therefore, exercises were not performed exclusively with machines (Johnson Health Tech, Taichung, Taiwan) and free weights, but also with elastic bands (Thera-Band).

During the adaptation period, the training load was adjusted by the rating of perceived exertion (RPE) method, using the adapted Borg scale (Day et al., 2004; Foster et al., 2001). The volunteers received a plasticized copy of the adapted Borg scale (Fos- ter et al., 2001) after the end of each set and were asked the following question: "How much exertion did you make during the performance of this exercise set?" Volunteers could either mention the exertion score or indicate it on the scale. The RPE was utilized to increase the external validity of the present study since this method is a reliable and easy to apply. Furthermore, this method allows the adjust of the load in each session of exercise.

After the adaptation period, volunteers were blinded to treatment allocation and were randomized into the PT or SS. Therefore, volunteers did not know in what treatment group they were allocated. Seventy-two hours before the begin of the experimental protocols, hemodynamic variables were measured at rest (as described below in the Hemodynamic measurements subtopic). Both sessions were designed with the same number and type of exercises. The exercises performed were: (a) squat on the chair $\left(90^{\circ}\right)$, (b) chest press, (c) seated leg curl, (d) frontal raise, (e) calf raise, (f) arm curl, (g) triceps extension, and (h) abdominal crunch. All exercises were performed in the total range of motion. In the beginning of every experimental session, all groups performed a brief warm-up that consisted of one set of 12-15 repetitions of each exercise without weights.

Both groups were equalized by the total volume of the session (i.e., the number of sets and repetitions); however, exercise intensity was different.

\section{Power training}

The exercise session of the PT was based on 3 sets of 8-10 repetitions of each exercise, at the intensity of 3 , which is considered moderate on the adapted Borg scale (Foster et al., 2001). This intensity represents approximately $50 \%$ of one-repetition maximum (1RM) (Day et al., 2004). One-minute rest interval was adopted between each set. The concentric phase should be performed as fast as possible, whereas the eccentric phase should be performed within 2 sec (Garber et al., 2011; Kraemer and Ratamess, 2004). To ensure the cadence of muscle contractions, a researcher was responsible for counting the time and feedback the volunteers during each muscle contraction, indicating if was necessary increase, decrease or maintain the velocity. In addition, before each concentric contraction, researchers stimulated the volunteers to perform the muscle contraction as fast as possible.

\section{Sham session}

The SS was based on 3 sets of $8-10$ repetitions of each exercise without elastic bands. One-minute rest interval was adopted between each set. The concentric and eccentric phases should be 
performed within 2 sec (Garber et al., 2011; Kraemer and Ratamess, 2004). To ensure the cadence of muscle contractions, a researcher was responsible for counting the time and feedback the volunteers during each muscle contraction, indicating if was necessary increase, decrease or maintain the velocity.

\section{Elastic bands}

The elastic bands were used to offer to the volunteers the possibility to perform the concentric contraction as fast as possible, avoiding any range-of-motion limitations imposed by the machines, since elastic bands propitiate large mobility in the achievement of the movement (Uchida et al., 2016). Elastic bands are portable, inexpensive, reliable, and has a high practical application (Martins et al., 2013; Uchida et al., 2016). Is important to mention, that the resistance of the elastic bands can be quantified in $\mathrm{kgf}$ (i.e., $1 \mathrm{kgf}=1 \mathrm{~kg}$ ), thus allowing the quantification of the external load (Uchida et al., 2016). Therefore, the using of elastic bands in the present study should be understanding as an advice, as machines and free weights, and not an independent variable. Volunteers of the present study performed the exercises using yellow and red elastic bands (Thera-Band).

All the elastic bands were warily used and, posteriorly, store according to the manufacturer's directions (Thera-Band), which can be viewed in http://www.thera-band.com/instructions.php.

\section{Activities of daily living}

In the present study, were proposed five tasks to mimic a common situation performed daily by older people. Therefore, an abstract narrative was created to the volunteers based on a previous interview performed with them about their routine activities throughout a normal day. In summary, was proposed to them imagine a situation where they were going to a grocery shop to buy food. After shopping, they should go home carrying two bags, placed the food in the kitchen cabinet, clean the home and make a seven-errors game. The five activities proposed were: 1 st walk 198 m, 2nd walk 198 m carrying two bags containing $8 \mathrm{~kg}$ ( $5 \mathrm{~kg}$ on the right arm and $3 \mathrm{~kg}$ on the left arm), 3 rd place 5 different weights $(3=3 \mathrm{~kg}, 2=2 \mathrm{~kg}$ ) at a time inside a $70-\mathrm{cm}$ stand, 4 th sweep the floor for $66 \mathrm{~m}$, 5 th perform a seven-errors game. To mimic the rest time that older adults usually perform between one task and another, a 2-min rest interval was adopted between each task. This period was also used to the evaluation of hemodynamic parameters.

The volunteers did not receive verbal encouragement to perform the tasks, once the proposal was that they accomplish the tasks as they are accustomed to doing daily. An illustration of the ADL can be observed in Fig. 1.

\section{Hemodynamic measurements}

In the morning of the experiment, upon arriving at the laboratory (8:30 a.m. to 10:30 a.m.), the participants were asked about any basic needs (i.e., drink water and use the bathroom) before the beginning of the experiments and were urged to avoid doing these activities during the experiments. Twenty minutes before the beginning of the experimental sessions, IA and during the intervals of the five tasks, the volunteers remained sitting down in a comfortable chair. The exercise room had an artificial light and automated control temperature $\left(24^{\circ} \mathrm{C}\right)$. The hemodynamic parameters were blindly measured on the left arm using automated oscillometric equipment (BP 3BT0A, Microlife AG, Widnau, Switzerland) and were recorded in the 21st min after 20 min of rest (rest), IA exercise completion, and in the intervals of each one of the five tasks, mentioned in the RESULTS section as 1st, 2nd, 3rd, 4th, and 5th. The hemodynamic parameters included systolic blood pressure (SBP) and diastolic blood pressure (DBP). The mean arterial pressure (MAP) and pulse pressure $(\mathrm{PP})$ were determined using the following equations: $\mathrm{MAP}=\mathrm{SBP}+(2 \times \mathrm{DBP} / 3)$ and $\mathrm{PP}$ $=\mathrm{SBP}-\mathrm{DBP}$. The procedures for the measurement of blood pressure were adapted from the VII Joint National Committee of High Blood Pressure (JNC7) (Chobanian et al., 2003) All evaluations were performed by the same investigator.

\section{Standard breakfast}

Volunteers reported to the laboratory after a 12 -hr fast. Food consumption was maintained constant during the previous $48 \mathrm{hr}$. Upon arriving at the laboratory, volunteers consumed a standard breakfast 60-90 min before the being of the experimental sessions. The kit was composed for a 43-g chocolate mini-cake (Casa Suiça, Jandira, Brazil), a 200-mL orange box juice (Ades, Unilever, Jundiaí, Brazil) and a 26-g brown crackers pack (Club Social). In total, $560 \mathrm{kcal}$ were offered from $85 \mathrm{~g}$ of carbohydrate, $13.1 \mathrm{~g}$ of fat, $4.96 \mathrm{~g}$ of protein and $662 \mathrm{mg}$ of sodium.

\section{Statistical analysis}

Normality of data was tested with Kormonov-Smirnov test. Intragroup and intergroup comparisons between the different moments (i.e., rest, IA, 1st, 2nd, 3rd, 4th, and 5th) on SBP, DBP, MAP, and PP were performed by Split-plot analysis of variance with Dunnett as post hoc test. Cohen effect size $d$ was calculated to inform clinical relevance of results. Effect size were defined to be moderate 

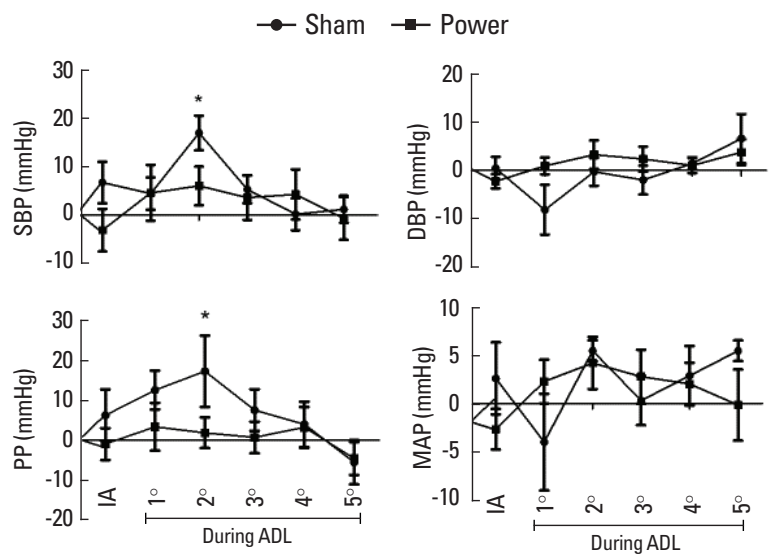

Fig. 2. Hemodynamic parameters at sham and power sessions. SBP, systolic blood pressure; DBP, diastolic blood pressure; MAP, mean arterial pressure; PP pulse pressure; $I A$, imediatelly after; $A D L$, activities of daily living. ${ }^{*} P=0.05$.

for values for Cohen $d$ of more than 0.2 but less than 0.5 , good for values between 0.5 and $\geq 0.8$. Level of significance was $5 \%$ $(P<0.05)$ and all procedures were performed using IBM SPSS Statistics ver. 20.0 (IBM Co., Armonk, NY, USA). The power of the sample size was determined using G*Power version 3.1.9.2 (Heinrich-Heine-Universität Düsseldorf, Düsseldorf, Germany) based on the magnitude of the mean differences in the 4 variables between the two groups to a level of significance set at $5 \%$ and power $(\beta)$ of 0.80 . Data are expressed in mean \pm standard deviation.

\section{RESULTS}

Table 1 shows the morphological and hemodynamic characteristics of older women recruited in the present study. As expected, all volunteers were older $(66.1 \pm 1.2)$. Body mass index evaluation indicates an overweight classification $\left(26.7 \pm 4.8 \mathrm{~kg} / \mathrm{m}^{2}\right)$. In turn, systolic $(133.9 \pm 23.4 \mathrm{mmHg})$ and diastolic blood pressure $(75.3 \pm 7.6$ $\mathrm{mmHg}$ ) values suggested a prehypertensive classification, which probably occurs due to sample composition (i.e., $55 \%$ of hypertensive and $45 \%$ of normotensive volunteers). Regarding drug class, angiotensin II receptor antagonist (80\%), calcium channel blockers (20\%), and diuretic (20\%) were the prevalent pharmacological treatment used by hypertensive patients. Volunteers attendance was $100 \%$ for all experimental sessions. Furthermore, volunteers did not present adverse effects during or after the experimental sessions.

In relation to physical effort, as expected, volunteers reported a higher session RPE at PT ( $3.0 \pm 0.0 \mathrm{AU}$; moderate) than during SS $(0.6 \pm 0.4 \mathrm{AU} ;$ rest $/$ very, very easy; $P<0.001)$. In concordance, total training workload (total number of sets $\times$ total number of repetitions $\times$ total weight lifted $[\mathrm{kg}])$ was higher at PT $(16,330 \mathrm{~kg})$ than

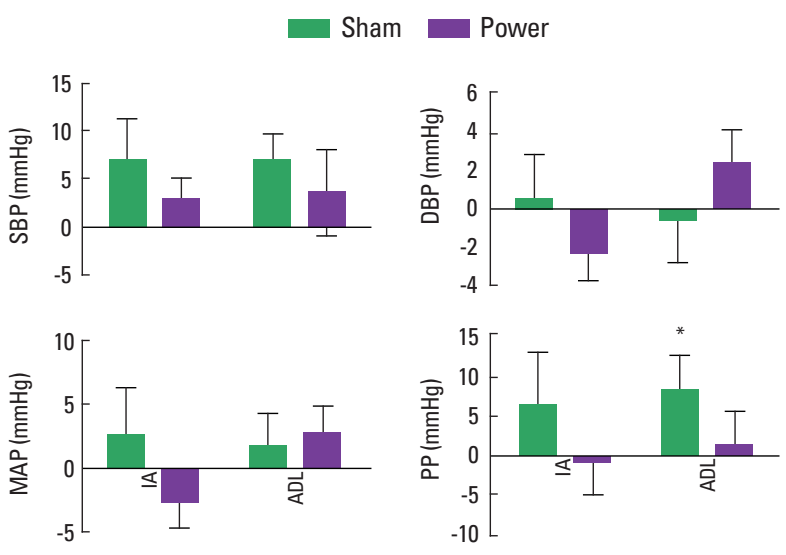

Fig. 3. Mean of hemodynamic parameters at sham and power sessions. SBP, systolic blood pressure; DBP, diastolic blood pressure; MAP, mean arterial pressure; $\mathrm{PP}$, pulse pressure; $\mathrm{IA}$, imediatelly after; $\mathrm{ADL}$, activities of daily living. ${ }^{*} P=0.05$.

during SS $(7,290 \mathrm{~kg} ; P<0.001)$.

Fig. 2 shows the behavior of hemodynamic parameters at PT and SS. DBP and MAP did not show significant differences in relation to rest moment, regardless the experimental session. However, SBP $(+17.0 \mathrm{mmHg} ; F=1.8$; Cohen $d=0.78)$ and $\mathrm{PP}(+17.2$ $\mathrm{mmHg} ; F=2.8$; Cohen $d=0.93$ ) were significantly increased after the second activity in comparison with the rest moment at SS. In turn, intragroup comparisons did not indicate significant differences in SBP and PP at PT session. There were no significant differences between PT and SS.

Fig. 3 shows the mean values of hemodynamic parameters IA the end of the exercise session and all the tasks. Analyze of variance and Dunnett post hoc test showed a significant increase in PP $(+7.8 \pm 10.8 \mathrm{mmHg})$ after $\mathrm{ADL}$ in comparison with rest moment at SS. In turn, SBP, DBP, and MAP did not show significant differences. Regarding Cohen $d$ evaluation, alterations on SBP and PP were classified as good (-0.76) and large (-0.94) during SS, respectively. On the other hand, during PT, a moderate (-0.37) classification was attributed to SBP, whereas PP behavior was unclassified because alterations were negligible (-0.09). Lastly, MAP and DBP were classified as moderate in both groups (PT: MAP $=-0.53$, $\mathrm{DB} P=-0.47 ; \mathrm{SS}: \mathrm{MAP}=-0.40, \mathrm{DB} P=0.23)$.

\section{DISCUSSION}

The main finding of the present study is that blood pressure values remain lower during the subsequent performance of tasks that mimic ADL in older women at PT in comparison with SS. Indeed, individual analyzes indicate that SBP $(-17.0 \mathrm{mmHg})$ and $\mathrm{PP}(-17.2 \mathrm{mmHg})$ remained lower after the second task, as well as 
pooled analyzes indicate that PP $(-7.8 \mathrm{mmHg})$ remained lower during the sum of all ADL when PT is compared with SS. These data confirm partially our initial hypothesis, once blood pressure values were not lower during the performance of all ADL. Data of the present study corroborate with other experiments, which demonstrate that after a session of physical exercise blood pressure values remain lower during the performance of a subsequent moderate intensity interval physical exercise (MacDonald et al., 2001), routine daily activities (Mota et al., 2009), mental stress (Hamer et al., 2006; Neves et al., 2012) and mental stress associated with physical effort (Ribeiro et al., 2011).

Regarding previous studies, in a seminal experiment, MacDonald et al. (2001) elegantly demonstrated that a prior achieved of moderate-intensity aerobic exercise (i.e., $70 \%$ of $\mathrm{VO}_{2 \text { peak }}$ ) is able to elicit significant lower SBP and DBP values during the performance of several physical tasks in comparison with the control session. In relation to resistance exercise, Mota et al. (2009) submitted hypertensive patients to a circuit model of resistance training, which was composed of 13 exercises that were performed once at $40 \%$ of 1RM. After physical exercise cessation, blood pressure values were measured during the free-living workday. Results demonstrated that blood pressure values remained lower during the $7 \mathrm{hr}$ following exercise cessation in comparison with control session.

However, despite the beneficial results observed in these experiments, several limitations associated with these studies must be mentioned, such as samples composed by healthy young and middle-age adults, and the subsequent performance of noncontrolled tasks (e.g., free-living workday). On the other hand, the present experiment underwent normotensive and hypertensive older women to a session of PT and a subsequent performance of tasks that mimic the ADL. Consequently, the present data advance previous knowledge, once our scientific approach seems to have a higher external validity, allowing greater inferences than the aforementioned experiments.

In fact, our sample was composed of normotensive and hypertensive older women, which strongly improves the clinical application of the present study in comparison with the other experiments, once the incidence of cardiovascular and cerebrovascular events is increased in older adults in comparison with young adults (Mozaffarian et al., 2015). Moreover, although until the 50 years of age the prevalence of cardiovascular risk factors is higher in men, postmenopause period and its neuro-humoral changes cause a shift in the curve in favor of women (Go et al., 2013), so that is possible observe an exponent increase in the frequency of some cardiovascular risk factors-such as elevated blood pres- sure-in postmenopause women.

In addition, in some experiments, the activities performed before the measurement of blood pressure values were not controlled (i.e., free-living workday) (Mota et al., 2009; Ribeiro et al., 2011), as well as, in others (MacDonald et al., 2001), the ADL selected to compose the experimental design can be discussed, once these were, predominately, based on aerobic component (e.g., walking on a treadmill at $4.8 \mathrm{~km} / \mathrm{hr}$ during $10 \mathrm{~min}$ ), which do not really reflecting the daily activities performed by older adults.

Regarding the regime of physical exercise, several evidence have demonstrated significant HPE, associated or not the performance of subsequent tasks, after aerobic and/or resistance exercises in older adults (MacDonald et al., 2001; Mota et al., 2009; Neves et al., 2012; Ribeiro et al., 2011). However, PT—which has been widely recommend for older adults, in an attempt to avoid, or even, minimizing the deleterious effects of aging on muscle mass, strength, power and functionality (i.e., primary sarcopenia) (American College of Sports Medicine et al., 2009; Garber et al., 2011) - has been poorly studied in this context and, for the best of our knowledge, there is a lack in the literature about the effects of a previous performance of a session of PT in the hemodynamic behavior during a subsequent performance of tasks that mimic ADL.

In fact, just recently, in a seminal experiment from our laboratory, the acute effects of PT with elastic bands in blood pressure values of normotensive and hypertensive older adults were elucidated (Coelho-Junior et al., 2017a). Results demonstrate a significant PEH during 35 min after exercise cessation (Coelho-Junior et al., 2017a). Therefore, data of the present study showed, for the first time, that hypotension post PT can be-at least, partiallypreserved during the subsequent performance of ADL. Interestingly, the protective effects of PT were not enough to avoid further increases in blood pressure values during the performance of the other tasks, once there were no differences among blood pressure values during PT session and SS. These data suggest that the mechanisms responsible for blood pressure lowering after PT cannot be sustained for a long time.

Unfortunately, possible mechanisms associated with the protective effects of PT in blood pressure values were not investigated in the present study. However, data from Coelho-Junior et al. (2017a) indicate that nitric oxide (NO) bioavailability is increased during $1 \mathrm{hr}$ after a unique session of PT in older women. These data have been also demonstrated by other studies, so that is possible infer that this molecule collaborates with the effects of PT observed in the present study (Asano et al., 2013; Asano et al., 2014; Santana et al., 2013). However, is important to mention that NO is not 
considered a short-term mechanism of blood pressure control. Thus, other mechanisms can be associated with the action of NO in the maintaining of lower blood pressure values during ADL, such as neural aspects (i.e., autonomous nervous system) (Feriani et al., 2017; Queiroz et al., 2015). Nevertheless, this hypothesis must be confirmed in the context of PT, once MacDonald et al. (2001) did not observe ameliorate heart rate variability during the performance of ADL after the end of the aerobic exercise.

Some limitations of the present study should be mentioned to collaborate with better inferences about the data. Regarding blood pressure measurement, in the present study, records occurred in the rest interval of the tasks. Thus, future studies should focus on direct (i.e., catheterization) or indirect moment to moment evaluations of blood pressure values. Moreover, the sample was composed of a mix of normotensive and hypertensive volunteers. It is well accepted that hypertensive subjects present higher decrease on blood pressure values than normotensive subjects (Gerage et al., 2015; Moraes et al., 2012), thereby is possible that the results of the present study cannot be extrapolated to normotensive individuals. Lastly, the possible mechanisms responsible for blood pressure maintaining after exercise should be investigated in future studies.

In summary, data of the present study indicate that an acute session of PT can maintain blood pressure values lower during the subsequent performance of tasks that mimic ADL in older women.

\section{CONFLICT OF INTEREST}

No potential conflict of interest relevant to this article was reported.

\section{ACKNOWLEDGMENTS}

BR received financial support from Conselho Nacional de Pesquisa e Desenvolvimento (CNPq-BPQ). The authors are also grateful to the Conselho Nacional de Desenvolvimento Científico e Tecnológico (CNPq) and Coordenação de Aperfeiçoamento de Pessoal de Nível Superior (CAPES) for the scholarships to DJF and $\mathrm{HJCJ}$, respectively.

\section{REFERENCES}

American College of Sports Medicine, Chodzko-Zajko WJ, Proctor DN, Fiatarone Singh MA, Minson CT, Nigg CR, Salem GJ, Skinner JS. American College of Sports Medicine position stand. Exercise and physical activity for older adults. Med Sci Sports Exerc 2009;41:1510-
1530.

Asano RY, Browne RA, Sotero RD, Sales MM, Moraes JF, Campbell CS, Simões $\mathrm{H}$. Cycling above rather than below lactate threshold is more effective for nitric oxide release and post-exercise blood pressure reduction in individuals with type-2 diabetes. Motriz: Rev Educ Fis 2013;19:633-640.

Asano RY, Sales MM, Browne RA, Moraes JF, Coelho Júnior HJ, Moraes MR, Simões HG. Acute effects of physical exercise in type 2 diabetes: a review. World J Diabetes 2014;5:659-665.

Barreto CB, Aguiar SS, Palmeira R, Coelho-Júnior HJ, Gargaglione EM, Oliveira JF, Pires FO, Asano RY. What is the minimun volume of aerobic physical exercise necessary to elicit postexercise hypotension? J Exerc Physiol Online 2015;18:1-12.

Bean JF, Leveille SG, Kiely DK, Bandinelli S, Guralnik JM, Ferrucci L. A comparison of leg power and leg strength within the InCHIANTI study: which influences mobility more? J Gerontol A Biol Sci Med Sci 2003;58:728-733.

Brito LC, Queiroz AC, Forjaz CL. Influence of population and exercise protocol characteristics on hemodynamic determinants of post-aerobic exercise hypotension. Braz J Med Biol Res 2014;47:626-636.

Carlson DJ, Dieberg G, Hess NC, Millar PJ, Smart NA. Isometric exercise training for blood pressure management: a systematic review and meta-analysis. Mayo Clin Proc 2014;89:327-334.

Chobanian AV, Bakris GL, Black HR, Cushman WC, Green LA, Izzo JL Jr, Jones DW, Materson BJ, Oparil S, Wright JT Jr, Roccella EJ; National Heart, Lung, and Blood Institute Joint National Committee on Prevention, Detection, Evaluation, and Treatment of High Blood Pressure; National High Blood Pressure Education Program Coordinating Committee. The seventh report of the Joint National Committee on prevention, detection, evaluation, and treatment of high blood pressure: the JNC 7 report. JAMA 2003;289:2560-2572.

Coelho-Junior HJ, Irigoyen MC, Aguiar SDS, Gonçalves IO, Câmara NOS, Cenedeze MA, Asano RY, Rodrigues B, Uchida MC. Acute effects of power and resistance exercises on hemodynamic measurements of older women. Clin Interv Aging 2017a;12:1103-1114.

Coelho-Junior HJ, Rodrigues B, Aguiar SD, Gonçalves IO, Pires FO, Asano RY, Uchida MC. Hypertension and functional capacities in community-dwelling older women: a cross-sectional study. Blood Press 2017b;26:156-165.

Coelho-Junior HJ, Rodrigues B, Feriani DJ, Gonçalves IO, Asano RY, Aguiar SD, Uchida MC. Effects of multicomponent exercise on functional and cognitive parameters of hypertensive patients: a quasi-experimental study. J Aging Res 2017c;2017:1978670.

Cornelissen VA, Smart NA. Exercise training for blood pressure: a systematic review and meta-analysis. J Am Heart Assoc 2013;2:e004473. 
Day ML, McGuigan MR, Brice G, Foster C. Monitoring exercise intensity during resistance training using the session RPE scale. J Strength Cond Res 2004;18:353-358.

Dietzel R, Gast U, Heine T, Felsenberg D, Armbrecht G. Cross-sectional assessment of neuromuscular function using mechanography in women and men aged 20-85 years. J Musculoskelet Neuronal Interact 2013;13:312-319.

Feriani DJ, Souza GIH, Carrozzi NM, Mostarda C, Dourado PMM, Consolim-Colombo FM, De Angelis K, Moreno H, Irigoyen MC, Rodrigues $\mathrm{B}$. Impact of exercise training associated to pyridostigmine treatment on autonomic function and inflammatory profile after myocardial infarction in rats. Int J Cardiol 2017;227:757-765.

Foster C, Florhaug JA, Franklin J, Gottschall L, Hrovatin LA, Parker S, Doleshal $\mathrm{P}$, Dodge $\mathrm{C}$. A new approach to monitoring exercise training. J Strength Cond Res 2001;15:109-115.

Garber CE, Blissmer B, Deschenes MR, Franklin BA, Lamonte MJ, Lee IM, Nieman DC, Swain DP; American College of Sports Medicine. American College of Sports Medicine position stand. Quantity and quality of exercise for developing and maintaining cardiorespiratory, musculoskeletal, and neuromotor fitness in apparently healthy adults: guidance for prescribing exercise. Med Sci Sports Exerc 2011;43:1334-1359.

Gerage AM, Ritti-Dias RM, do Nascimento MA, Pina FL, Gonçalves CG, Sardinha LB, Cyrino ES. Chronic resistance training does not affect post-exercise blood pressure in normotensive older women: a randomized controlled trial. Age (Dordr) 2015;37:63.

Go AS, Mozaffarian D, Roger VL, Benjamin EJ, Berry JD, Borden WB, Bravata DM, Dai S, Ford ES, Fox CS, Franco S, Fullerton HJ, Gillespie C, Hailpern SM, Heit JA, Howard VJ, Huffman MD, Kissela BM, Kittner SJ, Lackland DT, Lichtman JH, Lisabeth LD, Magid D, Marcus GM, Marelli A, Matchar DB, McGuire DK, Mohler ER, Moy CS, Mussolino ME, Nichol G, Paynter NP, Schreiner PJ, Sorlie PD, Stein J, Turan TN, Virani SS, Wong ND, Woo D, Turner MB; American Heart Association Statistics Committee and Stroke Statistics Subcommittee. Heart disease and stroke statistics--2013 update: a report from the American Heart Association. Circulation 2013;127:e6-245.

Hamer M, Taylor A, Steptoe A. The effect of acute aerobic exercise on stress related blood pressure responses: a systematic review and meta-analysis. Biol Psychol 2006;71:183-190.

Kraemer WJ, Ratamess NA. Fundamentals of resistance training: progression and exercise prescription. Med Sci Sports Exerc 2004;36:674688.

Lauretani F, Russo CR, Bandinelli S, Bartali B, Cavazzini C, Di Iorio A, Corsi AM, Rantanen T, Guralnik JM, Ferrucci L. Age-associated changes in skeletal muscles and their effect on mobility: an operational diagnosis of sarcopenia. J Appl Physiol (1985) 2003;95:1851-1860.
Liu S, Goodman J, Nolan R, Lacombe S, Thomas SG. Blood pressure responses to acute and chronic exercise are related in prehypertension. Med Sci Sports Exerc 2012;44:1644-1652.

MacDonald JR, Hogben CD, Tarnopolsky MA, MacDougall JD. Post exercise hypotension is sustained during subsequent bouts of mild exercise and simulated activities of daily living. J Hum Hypertens 2001;15: 567-571.

Macedo M, Silva AS, Olher RR, Coelho-Junior HJ, Palmeira R, Asano RY. Post-exercise hypotension between different protocols of resistance training for beginners. J Exerc Physiol Online 2014;17:58-65.

Martins WR, de Oliveira RJ, Carvalho RS, de Oliveira Damasceno V, da Silva VZ, Silva MS. Elastic resistance training to increase muscle strength in elderly: a systematic review with meta-analysis. Arch Gerontol Geriatr 2013;57:8-15.

Moraes MR, Bacurau RF, Ramalho JD, Reis FC, Casarini DE, Chagas JR, Oliveira V, Higa EM, Abdalla DS, Pesquero JL, Pesquero JB, Araujo $\mathrm{RC}$. Increase in kinins on post-exercise hypotension in normotensive and hypertensive volunteers. Biol Chem 2007;388:533-540.

Moraes MR, Bacurau RF, Simões HG, Campbell CS, Pudo MA, Wasinski F, Pesquero JB, Würtele M, Araujo RC. Effect of 12 weeks of resistance exercise on post-exercise hypotension in stage 1 hypertensive individuals. J Hum Hypertens 2012;26:533-539.

Moreira SR, Cucato GG, Terra DF, Ritti-Dias RM. Acute blood pressure changes are related to chronic effects of resistance exercise in medicated hypertensives elderly women. Clin Physiol Funct Imaging 2016;36: 242-248.

Mota MR, Pardono E, Lima LC, Arsa G, Bottaro M, Campbell CS, Simões HG. Effects of treadmill running and resistance exercises on lowering blood pressure during the daily work of hypertensive subjects. J Strength Cond Res 2009;23:2331-2338.

Mozaffarian D, Benjamin EJ, Go AS, Arnett DK, Blaha MJ, Cushman M, de Ferranti S, Després JP, Fullerton HJ, Howard VJ, Huffman MD, Judd SE, Kissela BM, Lackland DT, Lichtman JH, Lisabeth LD, Liu S, Mackey RH, Matchar DB, McGuire DK, Mohler ER 3rd, Moy CS, Muntner P, Mussolino ME, Nasir K, Neumar RW, Nichol G, Palaniappan L, Pandey DK, Reeves MJ, Rodriguez CJ, Sorlie PD, Stein J, Towfighi A, Turan TN, Virani SS, Willey JZ, Woo D, Yeh RW, Turner MB; American Heart Association Statistics Committee and Stroke Statistics Subcommittee. Heart disease and stroke statistics--2015 update: a report from the American Heart Association. Circulation 2015;131:e29322.

Neves FJ, Carvalho AC, Rocha NG, Silva BM, Sales AR, de Castro RR, Rocha JD, Thomaz TG, Nóbrega AC. Hemodynamic mechanisms of the attenuated blood pressure response to mental stress after a single bout of maximal dynamic exercise in healthy subjects. Braz J Med Biol Res 


\section{2;45:610-616.}

Pescatello LS, Franklin BA, Fagard R, Farquhar WB, Kelley GA, Ray CA; American College of Sports Medicine. American College of Sports Medicine position stand. Exercise and hypertension. Med Sci Sports Exerc 2004;36:533-553.

Queiroz AC, Sousa JC, Cavalli AA, Silva ND Jr, Costa LA, Tobaldini E, Montano N, Silva GV, Ortega K, Mion D Jr, Tinucci T, Forjaz CL. Post-resistance exercise hemodynamic and autonomic responses: Comparison between normotensive and hypertensive men. Scand J Med Sci Sports 2015;25:486-494.

Ramírez-Campillo R, Abad-Colil F, Vera M, Andrade DC, Caniuqueo A, Martínez-Salazar C, Nakamura FY, Arazi H, Cerda-Kohler H, Izquierdo M, Alonso-Martínez AM. Men and women exhibit similar acute hypotensive responses after low, moderate, or high-intensity plyometric training. J Strength Cond Res 2016;30:93-101.

Rhea MR. Determining the magnitude of treatment effects in strength training research through the use of the effect size. J Strength Cond Res 2004;18:918-920.

Ribeiro F, Campbell CS, Mendes G, Arsa G, Moreira SR, da Silva FM, Prestes J, da Costa Sotero R, Simões HG. Exercise lowers blood pres- sure in university professors during subsequent teaching and sleeping hours. Int J Gen Med 2011;4:711-716.

Santana HA, Moreira SR, Asano RY, Sales MM, Córdova C, Campbell CS, Espindola FS, Sposito AC, Nóbrega OT, Simões HG. Exercise intensity modulates nitric oxide and blood pressure responses in hypertensive older women. Aging Clin Exp Res 2013;25:43-48.

Terra DF, Mota MR, Rabelo HT, Bezerra LM, Lima RM, Ribeiro AG, Vinhal PH, Dias RM, Silva FM. Reduction of arterial pressure and double product at rest after resistance exercise training in elderly hypertensive women. Arq Bras Cardiol 2008;91:299-305.

Uchida MC, Nishida MM, Sampaio RA, Moritani T, Arai H. Thera-band ${ }^{\circledR}$ elastic band tension: reference values for physical activity. J Phys Ther Sci 2016;28:1266-1271.

Wallerstein LF, Tricoli V, Barroso R, Rodacki A LF, Russo L, Aihara AY, da Rocha Correa Fernandes A, de Mello MT, Ugrinowitsch C. Effects of strength and power training on neuromuscular variables in older adults. J Aging Phys Act 2012;20:171-185.

World Health Organization. Global health risks: mortality and burden of disease attributable to selected major risks. Geneva: World Health Organization; 2009. 